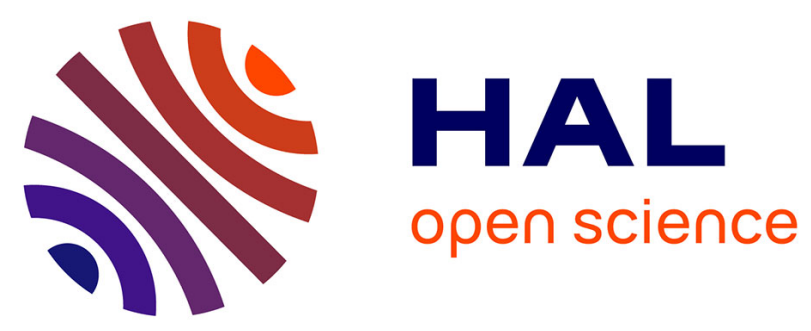

\title{
Balancing Benefit vs Risk of Immunosuppressive Therapy for Individual Patients With Inflammatory Bowel Diseases
}

Laurent Beaugerie, Julien Kirchgesner

\section{To cite this version:}

Laurent Beaugerie, Julien Kirchgesner. Balancing Benefit vs Risk of Immunosuppressive Therapy for Individual Patients With Inflammatory Bowel Diseases. Clinical Gastroenterology and Hepatology, 2019, 17, pp.370 - 379. 10.1016/j.cgh.2018.07.013 . hal-03484635

\section{HAL Id: hal-03484635 \\ https://hal.science/hal-03484635}

Submitted on 20 Dec 2021

HAL is a multi-disciplinary open access archive for the deposit and dissemination of scientific research documents, whether they are published or not. The documents may come from teaching and research institutions in France or abroad, or from public or private research centers.
L'archive ouverte pluridisciplinaire HAL, est destinée au dépôt et à la diffusion de documents scientifiques de niveau recherche, publiés ou non, émanant des établissements d'enseignement et de recherche français ou étrangers, des laboratoires publics ou privés.

\section{(ㄷ)(1) $\$$}

Distributed under a Creative Commons Attribution - NonCommerciall 4.0 International 
Balancing Benefit vs Risk of Immunosuppressive Therapy for Individual Patients With Inflammatory Bowel Diseases

Short title: Benefit-risk balance of immunosuppressive therapy in inflammatory bowel disease

Laurent Beaugerie (1) and Julien Kirchgesner (1)

(1) Department of Gastroenterology, AP-HP, Hôpital Saint-Antoine F-75012 and GRC-UPMC 03, Sorbonne Université, Paris, France

Funding: This work was not supported by dedicated funding.

\author{
Abbreviations used in this paper: \\ CD, Crohn's disease \\ CESAME, Cancers Et Surrisque Associé aux Maladies inflammatoires intestinales En France; \\ IBD, inflammatory bowel disease \\ JAK, Janus kinase \\ TNF, tumor necrosis factor \\ UC, ulcerative colitis \\ VTE, venous thromboembolism events
}

Corresponding author: Prof. Laurent Beaugerie, Service de Gastroentérologie et Nutrition, Hôpital Saint-Antoine, 184 rue du faubourg Saint-Antoine, 75571 Paris CEDEX 12, France. Tel: +3314928 31 71, Fax: +33149283188 
E-mail: laurent.beaugerie@aphp.fr

Disclosures: The authors disclose the following:

Laurent Beaugerie received consulting fees from Janssen, Pfizer and Allergan; lecture fees from Abbvie, Janssen, MSD, Ferring Pharmaceuticals, Mayoly-Spendler, Takeda and Tillots; and research support from Abbott, Ferring Pharmaceuticals, Hospira-Pfizer, Janssen, MSD, Takeda and Tillots. Julien Kirchgesner discloses no conflicts.

Author contributions: LB was responsible for the review concept and design. LB and JK were jointly responsible for the implementation and writing of the review.

Word count including abstract, text, figure and table legends, references: 5996 There was no funding source for the work The English of the article was revised via the Springer Nature language editing system. This was funded by the authors. 


\begin{abstract}
Inflammatory bowel diseases (IBD) and their treatments, particularly immunosuppressive drugs, increase risk of infections and cancers. However, by promoting mucosal healing, these agents should reduce risks of infections related to intestinal lesions, malnutrition, intravenous devices, and IBD surgeries and reduce risk of cancers associated with chronic mucosal inflammationalthough there are few data to support this concept. Corticosteroids increase the risk of vascular thromboembolic events, yet other immunosuppressive drugs that induce deep remission from IBD could decrease the incidence of cardiovascular events attributable to systemic inflammation and IBD-related hospitalizations and/or surgeries. The nature and magnitude of the risks of infections and cancers vary with immunosuppressive drug class and patient sex and age. For example, thiopurines increase risk of viral infections that might be fatal in young patients, whereas tumor necrosis factor antagonists increase risk of bacterial and intracellular infections that can be fatal in patients of any age, but particularly in older patients. The ability of drugs to prevent IBD-associated colorectal cancer varies with IBD location and duration. Models to assess the benefit:risk ratio of long-term use of immunosuppressive drugs for patients with IBD should be adapted based on patients' age, sex, and IBD phenotype, to properly guide patient management. The decision-making process should begin with a clear explanation of treatment risks and then integrate the patient's emotional perception of risks.
\end{abstract}

Key words: risk-benefit analysis, Crohn's disease, ulcerative colitis, emotional bias 
Crohns' disease (CD) and ulcerative colitis (UC) are characterized by continuous or relapsing intestinal inflammation. Both inflammatory bowel diseases (IBDs) are lifetime diseases. Most of the treatments that are currently used are anti-inflammatory drugs. These anti-inflammatory drugs, except 5-amino-salicylates, also exhibit immunosuppressive properties.

Immunosuppressive drugs that are used for the treatment of IBD include small molecules (corticosteroids, thiopurines, and methotrexate) and biologics (anti-Tumor Necrosis Factor (TNF) agents, vedolizumab, and ustekinumab). New biologics and immunosuppressive small molecules (Janus kinase (JAK) inhibitors and Sphingosine 1 phosphate receptor modulators) are under development. Because of the possible complications of immunosuppression, clinicians do not consider using these drugs on a lifetime basis. There is a growing trend towards a cyclic use of these drugs. When making the decision to enter a therapeutic cycle, clinicians and patients are interested in benefit-risk balance modeling studies, which should ideally integrate all benefits and risks associated with therapeutic strategies. This research area is recent in IBD. Major advances occurred within the last years because of growing access to medico-administrative databases and initiation of well-phenotyped observational cohorts.

\section{Potential impact of immunosuppressive therapy on morbidity and mortality in IBD}

In westernized countries, the two primary causes of death are cardiovascular disease and cancer. ${ }^{1}$ This is also true for individuals living with IBD. ${ }^{2}$ In developed countries, death by infection (mainly influenza and pneumonia) is twenty times less frequent than death by cancer. ${ }^{3}$ Patients with IBD may develop cancers, cardiovascular events and infections that are not related to IBD or IBD treatment, are attributable to IBD itself, or are attributable to IBD treatment. Immunosuppressive drugs have been shown to promote immunosuppression-related infections and cancers (Figure 1). Via mucosal healing, immunosuppressants are also candidates for reducing the incidence of infections related to IBD. Finally, with the exception of corticosteroids that increase the risk of vascular thromboembolic events, it is plausible that immunosuppressive 
drugs that lead to IBD deep remission could decrease the incidence of cardiovascular events attributable to IBD.

\section{Expression of the magnitude of risks attributable to IBD or IBD drugs}

The association between treatment exposure and outcomes of interest may be expressed in relative terms, such as relative risks or odds ratios. The absolute risk is the probability of the occurrence of a specified outcome within a period of time (incidence rate). Incidence rates are generally expressed as the number of events per patient-years. The denominator of 1000 persons-years is increasingly used in the IBD literature. The number of events per 1000 years represents the risk percentage of developing the event for a 10-year period.

For physicians, absolute and relative risks are complementary approaches for the integration of medical knowledge. In contrast, when considering an individual patient in clinical practice, absolute risks are exclusively relevant for determining the individual benefit-risk balance of a therapeutic strategy.

Figure 2 plots the magnitudes of the risks of key events that may be observed in individuals with IBD on a logarithmic scale. For each event category, numbers are the sum of events not related to IBD or IBD treatment, related to IBD, or related to IBD treatment. The qualifying adjectives that appear in the figure are those used by drug agencies for stratifying the magnitude of risks of adverse events associated with the use of new drugs. ${ }^{4}$

\section{Data sources for assessing the magnitude of risks associated with IBD or IBD treatment.}

The incidence of frequent events in IBD may be adequately estimated in reports from IBD centers or meta-analyses of randomized controlled trials. To estimate the risks of rare events, such as opportunistic infections or cancers, the minimum time of observation needed often exceeds 30,000 patient-years. This power may be attained in studies from medico-administrative databases or observational cohorts. Subgroup assessment of the risks according to age-class 
and gender is possible in all studies. However, differential assessment of risks according to IBD phenotype is not possible in studies from most of the medico-administrative databases because data on IBD phenotype are lacking. To fill in this gap, data on IBD phenotype are recorded in dedicated prospective observational cohorts, such as CESAME or I-CARE ((Ibd CAncer and seRious infections in Europe, https://clinicaltrials.gov/ct2/show/NCT02377258).

\section{Infections}

Infections are extremely frequent in everyday life and can be categorized according to their clinical impact (Table 1). Serious infections are generally defined as infections that require hospitalization and may be life-threatening or result in permanent disability. In the IBD population, the incidence of serious infections ranges from 10 to 100 events per 1000 patientyears according study designs and care pathway specificities. ${ }^{5-7}$

Opportunistic infections occur selectively or are particularly severe in immune-compromised patients, and these infections are life-threatening. There is no universal list of opportunistic infections, and infections considered in the analyses vary among studies. ${ }^{6,8}$

Notably, the same infectious agent, for example zoster, may cause benign, serious or opportunistic infections according to host and context specificities and disease severity.

\section{Infections promoted by immunosuppressive therapy}

The excess risk of infection in patients with IBD exposed to corticosteroids, thiopurines and antiTNF varies among types of infection and drug classes (Table 2). Few data exist on everyday benign infections. It was reported in a prospective cohort of outpatients with IBD that exposure to thiopurines was associated with an increased incidence of skin herpes flares and skin viral warts. ${ }^{9}$ The incidence of zoster is intrinsically increased in patients with IBD. ${ }^{10-12}$ Exposure to corticosteroids, thiopurines, and/or anti-TNF agents further increases this risk. ${ }^{10-12}$ A similar excess risk of serious infections in patients exposed to monotherapies with thiopurines 
and anti-TNF agents was reported in a meta-analysis of randomized controlled trials. ${ }^{13}$ The excess risk primarily relates to viral infections in patients exposed to monotherapy with thiopurines. ${ }^{5}$ The risk of serious infections is even higher in patients exposed to corticosteroids or combination therapy with thiopurines and anti-TNF agents. ${ }^{5,14}$ There is an excess risk of opportunistic infections in patients exposed to monotherapies with thiopurines and anti-TNF agents..$^{5,6,8,13,15,16}$ This risk is significantly higher in patients exposed to corticosteroids ${ }^{7,14,17}$ or combination therapy with thiopurines and anti-TNF agents. ${ }^{5}$

There is an excess risk of all types of infections in patients exposed to corticosteroids and/or anti-TNF agents, particularly older patients. ${ }^{17,18}$ In contrast, the excess risk primarily relates to viral infections in patients exposed to thiopurines. ${ }^{5}$ There is no excess mortality from infection at the population level in IBD patients exposed to thiopurines and anti-TNF agents, 7,17,19 but some studies have reported an excess mortality from infection in patients exposed to corticosteroids. $^{7,14,17}$ At an individual level, thiopurine-associated fatal infections have been reported mainly in young patients. These infections include severe forms of varicella ${ }^{20}$ and primary Epstein-Barr virus or cytomegalovirus infections complicated with hemophagocytic lymphohistiocytosis. ${ }^{21}$ In patients exposed to anti-TNF agents, fatal cases of infections are related to various types of opportunistic infections, ${ }^{16}$. There are no data on the risk of infection in patients exposed to monotherapy with methotrexate in IBD. The first safety reports on vedolizumab in patients with IBD do not suggest an increased risk of serious infections. ${ }^{22}$ Data on infections in patients with IBD exposed to ustekinumab are lacking. However, no evidence of excess infections in patients receiving ustekinumab for psoriasis was reported. ${ }^{23}$ Patients exposed to JAK inhibitors for UC are at substantial increased risk of herpes zoster, giving sense to vaccination strategies. ${ }^{24}$ 
In controlled trials, patients exposed to immunosuppressive drugs who achieve mucosal healing should be at reduced risk of infections related to intestinal lesions compared to patients with uncontrolled disease. Patients exposed to thiopurines and/or anti-TNF exhibit an increased risk of immunosuppressive drug-related infections. These counterbalancing effects result in an overall similar incidence of infections in patients exposed to placebo and anti-TNF agents and/or thiopurines. ${ }^{13,25}$

\section{Cancers}

Cancers promoted by immunosuppressive therapy

The excess risk of cancer in patients with IBD exposed to corticosteroids, thiopurines and antiTNF agents varies among organs and drug classes (Table 3). Patients with IBD exposed to thiopurines exhibit a mild overall excess risk of cancers. ${ }^{26}$ All patients with IBD treated with thiopurines are at increased risk of EBV-associated lymphoma. ${ }^{27}$ Young patients, particularly males, are at risk of post-mononucleosis lymphomas and hepatosplenic T-cell lymphomas. ${ }^{28,29}$ IBD patients exposed to thiopurines exhibit an increased risk of non-melanocytic skin cancers, ${ }^{30,31}$ and patients exposed to anti-TNF agents are at increased risk of melanoma. ${ }^{30}$ Older men with IBD exposed to thiopurines are at increased risk of urinary tract cancers. ${ }^{26,32}$ Whether patients treated with anti-TNF agents alone exhibit an excess risk of lymphoma remains controversial. ${ }^{33,34}$ Patients treated with methotrexate for diseases other than IBD may develop reversible EBV-related lymphomas. ${ }^{35}$ Safety data from patients treated with vedolizumab and ustekinumab in IBD are not yet powered to address the risks of cancer associated with the long-term drug exposure.

\section{Chemopreventive effect of immunosuppressive therapy on cancers}

Patients with IBD may specifically develop cancers in segments of the digestive tract that are chronically inflamed. ${ }^{28}$ Subgroup analyses studies revealed no increased risk of colorectal 
cancer, ${ }^{36}$ small bowel adenocarcinoma, ${ }^{37}$ anal canal cancer, ${ }^{38}$ and cholangiocarcinoma, ${ }^{39}$ in patients with IBD compared to age- and gender-matched individuals in the general population when the digestive organs are not chronically inflamed. In contrast, a marked increase in the risk of digestive tract cancers is observed when digestive organs are chronically inflamed. ${ }^{36-39}$ Among immunosuppressive drugs used in IBD, thiopurines and methotrexate have been used in oncology as cytotoxic drugs, but these drugs have not exhibited effects on carcinogenesis itself. However, all immunosuppressive drugs used in IBD can reduce inflammation in intestinal segments that are affected by IBD, which could reduce in turn the risk of inflammation-related cancers. A chemopreventive effect of thiopurines in the risk of colorectal cancer in patients with UC has been reported in two nationwide cohorts. In the CESAME cohort, the adjusted hazard ratio for colorectal high-grade dysplasia or cancer among patients with longstanding extensive colitis was 0.28 for those who received thiopurines. ${ }^{36}$ In the ENEIDA cohort, the use of thiopurines was associated with a decreased risk of colorectal advanced neoplasia by multivariate analysis. ${ }^{40}$ No data from adequately powered cohorts are available for anti-TNF, vedolizumab or ustekinumab in this context.

\section{Cardiovascular events}

The increased risk of venous thromboembolism (VTE) is established in patients with IBD. Deep vein thrombosis and pulmonary embolism are the most common types of VTE. Population-based cohorts revealed a 1.5- to 3-fold higher risk for the development of VTE in patients with IBD compared to non-IBD controls. ${ }^{41}$ The highest risks are reported in patients with IBD flare, outside the hospital and without thromboprophylaxis. ${ }^{42}$

Patients with IBD exposed to systemic corticosteroids exhibit an increased risk of VTE. ${ }^{43,44}$ A recent meta-analysis of the few existing studies assessed the impact of anti-TNF agents compared to corticosteroids on the risk of VTE. It was reported in this meta-analysis a $70 \%$ 
decrease in the risk of VTE in patients with IBD treated with anti-TNF agents compared with those treated with corticosteroids. ${ }^{44}$

Acute arterial events include ischemic heart disease, cerebrovascular disease and peripheral artery disease. In population-based studies of patients with IBD, the incidence rate of acute arterial events range from five to ten events per 1000 patient-years. ${ }^{45,46} \mathrm{~A}$ recent nationwide study reported an increased risk of acute arterial events in CD and UC compared to the general population. ${ }^{46}$ The excess risk was higher in $C D$ than UC, and the highest excess risks were observed in younger patients in both IBD subtypes. Clinical disease activity of IBD is associated with an increased risk of acute arterial events in both IBD subtypes after adjustment for all traditional cardiovascular risk factors. The risk increased by 1.5 - to 2 -fold during periods of active disease. ${ }^{45,46}$ The differences observed in subgroup analyses may be due to various respective impacts of systemic inflammation and traditional cardiovascular risk factors. ${ }^{46,47}$

It is established that exposure to corticosteroids is associated with an increased risk of acute arterial events in $\mathrm{IBD}^{14,48}$ By contrast, it has been hypothesized that other immunosuppressive drugs that are used in chronic inflammatory diseases could decrease the incidence of acute arterial events. This has been demonstrated for myocardial infarction in patients exposed to methotrexate or anti-TNF agents in rhumatology. ${ }^{49}$ Data from the French national medicoadministrative database also suggest a significant reduction in the incidence of acute arterial events in patients with IBD exposed to combination therapy with anti-TNF agents and thiopurines. ${ }^{50}$

\section{Assessment of the benefit-risk balance of immunosuppressive therapy in IBD}

Merging all of the findings on the benefits and risks of IBD immunosuppressive therapy is difficult for clinicians. Treatment benefits are reported in randomized controlled trials, and treatment risks or indirect treatment benefits (e.g., chemoprevention, cardiovascular protection) are reported in observational studies. One unique tool is adapted to combine all findings and aid clinical 
decision-making. Clinical decision models were developed initially in the field of costeffectiveness analyses. ${ }^{51}$ State-transition models, ${ }^{51}$ including the Markov model, ${ }^{52}$ are the most commonly used models in the field of IBD. ${ }^{53-55}$

\section{Time-scale to assess the benefit-risk balance of immunosuppressive therapy}

The time-scale over which outcomes are assessed is the time horizon. ${ }^{51}$ Guidelines recommend a time horizon that is sufficiently long to capture differences in outcomes across treatment strategies. ${ }^{51}$ Since IBDs are lifetime diseases, the time horizon may be a lifetime. However, the time horizon that may be considered clinically relevant in IBD is the period of drug exposure because treatment-related benefits and risks generally do not persist after drug withdrawal. The concept of treatment cycle is emerging in the field of IBD, ${ }^{56}$ but there is no clear cut-off for the duration of one treatment cycle. A time horizon of 5 years may be relevant to assess most treatment strategies, but the relevant duration may vary in specific situations, such as induction therapies (short-term assessment) or surgical strategies (long-term assessment).

\section{Outcomes of interest}

The highest priority in the overall management of individuals with IBD is to avoid death due to IBD or IBD drugs. Therefore, the primary health outcome is life expectancy. However, events that are not at risk of death are not considered in this model, but some events, such as permanent stomas, highly affect patients' lives.

Alternatively, quality of life may be used as the health outcome. The 'utility' associated with health states was introduced to estimate gains in Quality-Adjusted Life Years (QALYs). ${ }^{57}$ In the field of inflammatory bowel disease, estimates of utility that are currently available are sparse and heterogeneous. ${ }^{58}$

Key parameters to be included in the benefit-risk assessment 
Personalized information on all risks and benefit parameters should become the standard of quality for guiding individual decision-making processes of treatment strategy. The historical evolution of decision models to assess the risk of lymphoma in patients with IBD exposed to thiopurines may illustrate this point. One of the first decision models published assessed the impact of thiopurines in patients with CD who achieved remission with corticosteroids. ${ }^{53}$ This study provided subgroups analyses according to age only. Another study modeled the impact of the combination of infliximab with azathioprine compared to infliximab alone, and the risk of lymphoma was estimated according to age and gender. ${ }^{54}$ Finally, in a recent study modeling the benefit-risk balance of continuing or withdrawing thiopurines in $C D$, the beneficial effect of thiopurines on colorectal cancer in the subgroup of patients with longstanding extensive colitis was also considered, with a substantial impact on results (Figure 3). ${ }^{55}$ Future studies should increasingly provide subgroup analyses based on age, gender, and IBD phenotype to improve the precision of estimates from medical decision-making models in IBD.

Special situations that deserve specific assessments of the benefit-risk balance of immunosuppressive therapy

Patients over the age of 65 years have the highest risks of morbidity and mortality due to uncontrolled IBD, such as $\mathrm{VTE}^{59}$ or perioperative death in UC. ${ }^{60}$ Older patients are also at maximal risk of cancers attributable to thiopurines, ${ }^{27}$ and serious and opportunistic infections due to corticosteroids, thiopurines and anti-TNF agents. ${ }^{5,18}$ In this context, the use of new biologics (vedolizumab and ustekinumab) and small molecules (JAK inhibitors) is attractive as long as no significant risk of cancer or death by infection has been demonstrated in the early development of these drugs. However, prudence is still required because older patients are usually not enrolled in randomized controlled trials and meta-analyses.

Additional elements must be taken into account in older patients. ${ }^{61}$ Priority could be given to reduce disabling digestive symptoms in patients often suffering from other disabling 
comorbidities. In addition, treat-to-target and endoscopic surveillance strategies that aim to reduce the incidence of long-term complications of disease complications are often less crucial in patients with limited life-expectancy, due to age and comorbidities, particularly in patient with late-onset disease.

Pregnancy is another specific context. It is generally recommended that an active treatment should be maintained throughout pregnancy in women with chronic uncontrolled, or partially controlled, disease. ${ }^{62,63}$. Regarding the choice of drugs, it is established that thalidomide and methotrexate are contra-indicated because of their teratogenic effects. The use of corticosteroids, thiopurines and anti-TNF agents is considered at low risk during pregnancy, while the safety of vedolizumab, ustekinumab and JAK inhibitors is not established, due to a lack of data.

In patients with previous cancer, it is questionable whether continuation or resumption of immunosuppressive therapy could promote cancer recurrence. No obvious excess risk of cancer recurrence has been reported in patients with chronic immune disease exposed to immunosuppressive therapy, ${ }^{64}$ although significant propensity biases cannot be excluded. ${ }^{65}$ Based mainly on a precautionary principle, it is recommended to try to respect a 2 to 5 -year pause in immunosuppressive therapy, according to the intrinsic risk of cancer recurrence, in patients with IBD after completion of cancer treatment. ${ }^{29}$ However, in patients with severely active uncontrolled IBD, life-threatening risks of uncontrolled IBD are superior to putative risks of cancer recurrence.

\section{Decision-making process}

\section{Communication on risks}

When two or more alternative therapeutic strategies may be considered in a given individual with IBD, the first step of the shared decision-making process is to explain the risks of IBD and IBD drugs to patients. Some general recommendations have been proposed ${ }^{66}$ based on the results 
of dedicated surveys. Descriptive words (rare, very rare) should be avoided because absolute numbers associated with these adjectives vary considerably among individuals. Relative risks are difficult to conceptualize. When absolute risks are expressed as numbers, consistent denominators (e.g., number of events per 1000 person-years, see above) should be preferred. Finally, visual depiction of risks, such as the 'thousand people shapes', should be used as often as possible.

\section{Communication on benefits}

An equilibrated communication on the benefit-risk balance of different strategies should include equal parts of information on the risks of IBD drugs and the risks of uncontrolled IBD that may be attenuated or suppressed by the use of IBD drugs (Figure 1). ${ }^{67}$

\section{Decision-making process and emotional component}

The magnitude of treatment risks that patients with IBD are willing to accept for a better control of IBD and an improved quality of life is a personal and subjective choice. Previous studies demonstrated that children with IBD and their parents and adults with IBD and gastroenterologists generally accept relatively high levels of risks of IBD drugs when IBD is severe. ${ }^{68,69}$ Individual emotional and personality factors may modulate or reverse final individual patient decisions. The therapeutic alternative that is associated with the best quality of lifeadjusted life expectancy may be rejected because of irrational or emotional individual perception. For example, many individuals prefer to travel by car over traveling by plane despite the fact that the objective risk of dying in ground transportation is much higher. Psychosocial sciences have also demonstrated that individuals are more prone to accept long-term risks than short-term risks of the same magnitude. Gastroenterologists should be aware of the major role of patient emotions and personality and try to integrate these factors when talking about the benefits and risks of therapies with their patients.

\section{Conclusion}


In patients with severely active IBD, potential complications of IBD generally outweigh the potential complications of IBD drugs on a short-term basis, which results in a favorable benefitrisk balance of most IBD drugs. In contrast, in patients with sustained deep remission thanks to immunosuppressive therapy, the long-term cumulative risks of IBD drugs may outweigh the risks associated with disease relapse. Long-term risks of immunosuppressive drugs are strongly ageand gender-dependent. For example, drug-induced serious infections and thiopurine-associated lymphomas are at the highest frequency in older patients. ${ }^{5,18}$ Regarding gender, the standardized incidence ratio of lymphoma in men exposed to thiopurines is approximately twice the standardized incidence ratio in women exposed to thiopurines. ${ }^{27}$ As a consequence, safety data that foster benefit-risk individual discussions should be tailored to age classes and gender. Intestinal cancers complicating IBD inflammation may be at least partially prevented with a sustained mucosal healing of intestinal lesions, and the magnitude of this potential benefit of IBD drugs should be progressively quantified in the near future. Moving progressively towards a personalized assessment of the benefit-risk balance of immunosuppressive IBD drugs is a prerequisite for a high-quality shared decision-making process on individual therapeutic strategies in patients with IBD. 
Figure legends

Figure 1. Primary complications of immunosuppressive therapy used in inflammatory bowel disease (deleterious impact) and potential reduction in the incidence of complications of inflammatory bowel disease due to the anti-inflammatory effect of immunosuppressive therapy (beneficial impact).

Figure 2. Magnitude of the risks of infections, cancers and vascular events in the population of patients with inflammatory bowel disease. Numbers of events per 1000 patient-years are plotted using a logarithmic scale. For each event category, numbers are the sum of events not related to $\mathrm{IBD}$ or IBD treatment, related to IBD, or related to IBD treatment. Adjectives that qualify risk levels are used by drug agencies.

Figure 3. Lifetime absolute risks of lymphoma and colorectal cancer associated with continuing (C) or withdrawing (W) maintenance therapy with thiopurines in patients with $C D$ in sustained clinical remission, according to age, gender and colonic extent (more or less than $50 \%$ of the mucosal surface ever involved) at the time of the decision. Adapted from Kirchgesner et al..$^{55}$ 


\section{References}

1. Heron M, Anderson RN. Changes in the Leading Cause of Death: Recent Patterns in Heart Disease and Cancer Mortality. NCHS Data Brief 2016:1-8.

2. Jess $T$, Frisch $M$, Simonsen J. Trends in overall and cause-specific mortality among patients with inflammatory bowel disease from 1982 to 2010. Clin Gastroenterol Hepatol 2013;11:43-48.

3. Murphy SL, Xu J, Kochanek KD, et al. Deaths: Final Data for 2015. Natl Vital Stat Rep Cent Dis Control Prev Natl Cent Health Stat Natl Vital Stat Syst 2017;66:1-75.

4. Anon. Guidelines for Preparing Core Clinical-Safety Information on Drugs - Report of CIOMS Working Group III • COUNCIL FOR INTERNATIONAL ORGANIZATIONS OF MEDICAL SCIENCES. Counc Int Organ Med Sci. Available at: https://cioms.ch/shop/product/guidelines-preparing-core-clinicalsafety-information-drugs-report-cioms-working-group-iii/ [Accessed February 21, 2018].

5. Kirchgesner J, Lemaitre M, Carrat F, et al. Risk of Serious and Opportunistic Infections Associated With Treatment of Inflammatory Bowel Diseases. Gastroenterology 2018.

6. Nyboe Andersen N, Pasternak B, Friis-Moller N, et al. Association between tumour necrosis factoralpha inhibitors and risk of serious infections in people with inflammatory bowel disease: nationwide Danish cohort study. BMJ 2015;350:h2809.

7. Lichtenstein GR, Feagan BG, Cohen RD, et al. Serious infections and mortality in association with therapies for Crohn's disease: TREAT registry. Clin Gastroenterol Hepatol 2006;4:621-630.

8. Toruner M, Loftus EV, Harmsen WS, et al. Risk factors for opportunistic infections in patients with inflammatory bowel disease. Gastroenterology 2008;134:929-36.

9. Seksik P, Cosnes J, Sokol $\mathrm{H}$, et al. Incidence of benign upper respiratory tract infections, HSV and HPV cutaneous infections in inflammatory bowel disease patients treated with azathioprine. Aliment Pharmacol Ther 2009;29:1106-13.

10. Gupta G, Lautenbach E, Lewis JD. Incidence and risk factors for herpes zoster among patients with inflammatory bowel disease. Clin Gastroenterol Hepatol 2006;4:1483-90.

11. Long MD, Martin C, Sandler RS, et al. Increased risk of herpes zoster among 108604 patients with inflammatory bowel disease. Aliment Pharmacol Ther 2013;37:420-429.

12. Khan N, Patel D, Trivedi C, et al. Overall and Comparative Risk of Herpes Zoster With Pharmacotherapy for Inflammatory Bowel Diseases: A Nationwide Cohort Study. Clin Gastroenterol Hepatol 2018.

13. Bonovas S, Fiorino G, Allocca M, et al. Biologic Therapies and Risk of Infection and Malignancy in Patients With Inflammatory Bowel Disease: A Systematic Review and Network Meta-analysis. Clin Gastroenterol Hepatol 2016. 
14. Lewis JD, Scott FI, Brensinger CM, et al. Increased Mortality Rates With Prolonged Corticosteroid Therapy When Compared With Antitumor Necrosis Factor- $\alpha$-Directed Therapy for Inflammatory Bowel Disease. Am J Gastroenterol 2018.

15. Ford AC, Peyrin-Biroulet L. Opportunistic infections with anti-tumor necrosis factor-alpha therapy in inflammatory bowel disease: meta-analysis of randomized controlled trials. Am J Gastroenterol 2013;108:1268-76.

16. Salmon-Ceron D, Tubach F, Lortholary O, et al. Drug-specific risk of non-tuberculosis opportunistic infections in patients receiving anti-TNF therapy reported to the 3-year prospective French RATIO registry. Ann Rheum Dis 2011;70:616-623.

17. Lichtenstein GR, Feagan BG, Cohen RD, et al. Serious infection and mortality in patients with Crohn's disease: more than 5 years of follow-up in the TREAT registry. Am J Gastroenterol 2012;107:1409-22.

18. Cottone $\mathrm{M}$, Kohn A, Daperno $\mathrm{M}$, et al. Advanced age is an independent risk factor for severe infections and mortality in patients given anti-tumor necrosis factor therapy for inflammatory bowel disease. Clin Gastroenterol Hepatol 2011;9:30-5.

19. Hutfless SM, Weng $X$, Liu L, et al. Mortality by medication use among patients with inflammatory bowel disease, 1996-2003. Gastroenterology 2007;133:1779-1786.

20. Springfeld C, Sauerbrei A, Filusch A, et al. Fatal varicella in an immunocompromised adult associated with a European genotype E2 variant of varicella zoster virus. J Clin Virol Off Publ Pan Am Soc Clin Virol 2009;44:70-73.

21. Biank VF, Sheth MK, Talano J, et al. Association of Crohn's disease, thiopurines, and primary epstein-barr virus infection with hemophagocytic lymphohistiocytosis. J Pediatr 2011;159:808-12.

22. Colombel J-F, Sands BE, Rutgeerts $P$, et al. The safety of vedolizumab for ulcerative colitis and Crohn's disease. Gut 2017;66:839-851.

23. Yiu ZZN, Exton LS, Jabbar-Lopez Z, et al. Risk of Serious Infections in Patients with Psoriasis on Biologic Therapies: A Systematic Review and Meta-Analysis. J Invest Dermatol 2016;136:15841591.

24. Colombel J-F. Herpes Zoster in Patients Receiving JAK Inhibitors For Ulcerative Colitis: Mechanism, Epidemiology, Management, and Prevention. Inflamm Bowel Dis 2018.

25. Lichtenstein $\mathrm{GR}$, Diamond $\mathrm{RH}$, Wagner $\mathrm{CL}$, et al. Clinical trial: benefits and risks of immunomodulators and maintenance infliximab for IBD-subgroup analyses across four randomized trials. Aliment Pharmacol Ther 2009;30:210-226.

26. Pasternak B, Svanström $\mathrm{H}$, Schmiegelow $\mathrm{K}$, et al. Use of azathioprine and the risk of cancer in inflammatory bowel disease. Am J Epidemiol 2013;177:1296-1305. 
27. Kotlyar DS, Lewis JD, Beaugerie L, et al. Risk of lymphoma in patients with inflammatory bowel disease treated with azathioprine and 6-mercaptopurine: a meta-analysis. Clin Gastroenterol Hepatol 2015;13:847-858.e4; quiz e48-50.

28. Beaugerie L, Itzkowitz SH. Cancers Complicating Inflammatory Bowel Disease. N Engl J Med 2015;373:195.

29. Annese V, Beaugerie L, Egan L, et al. European Evidence-based Consensus: Inflammatory Bowel Disease and Malignancies. J Crohns Colitis 2015;9:945-965.

30. Long MD, Martin CF, Pipkin CA, et al. Risk of melanoma and nonmelanoma skin cancer among patients with inflammatory bowel disease. Gastroenterology 2012;143:390-399.e1.

31. Peyrin-Biroulet L, Khosrotehrani K, Carrat F, et al. Increased risk for nonmelanoma skin cancers in patients who receive thiopurines for inflammatory bowel disease. Gastroenterology 2011;141:1621-1628.e1-5.

32. Bourrier A, Carrat F, Colombel J-F, et al. Excess risk of urinary tract cancers in patients receiving thiopurines for inflammatory bowel disease: a prospective observational cohort study. Aliment Pharmacol Ther 2016;43:252-261.

33. Nyboe Andersen N, Pasternak B, Basit S, et al. Association between tumor necrosis factor- $\alpha$ antagonists and risk of cancer in patients with inflammatory bowel disease. JAMA 2014;311:24062413.

34. Lemaitre M, Kirchgesner J, Rudnichi A, et al. Association Between Use of Thiopurines or Tumor Necrosis Factor Antagonists Alone or in Combination and Risk of Lymphoma in Patients With Inflammatory Bowel Disease. JAMA 2017;318:1679-1686.

35. Kamel OW, Rijn $M$ van de, Weiss $L M$, et al. Brief report: reversible lymphomas associated with Epstein-Barr virus occurring during methotrexate therapy for rheumatoid arthritis and dermatomyositis. N Engl J Med 1993;328:1317-1321.

36. Beaugerie L, Svrcek M, Seksik P, et al. Risk of colorectal high-grade dysplasia and cancer in a prospective observational cohort of patients with inflammatory bowel disease. Gastroenterology 2013;145:166-175.e8.

37. Elriz K, Carrat F, Carbonnel F, et al. Incidence, presentation, and prognosis of small bowel adenocarcinoma in patients with small bowel Crohn's disease: a prospective observational study. Inflamm Bowel Dis 2013;19:1823-1826.

38. Beaugerie L, Carrat F, Nahon S, et al. High risk of anal and rectal cancer in patients with anal and/or perianal Crohn's disease. Clin Gastroenterol Hepatol 2017.

39. Sørensen $\rfloor \emptyset$, Nielsen $\mathrm{OH}$, Andersson $\mathrm{M}$, et al. Inflammatory bowel disease with primary sclerosing cholangitis: A Danish population-based cohort study 1977-2011. Liver Int 2017. 
40. Gordillo J, Cabré E, Garcia-Planella E, et al. Thiopurine Therapy Reduces the Incidence of Colorectal Neoplasia in Patients with Ulcerative Colitis. Data from the ENEIDA Registry. J Crohns Colitis 2015;9:1063-1070.

41. Yuhara $\mathrm{H}$, Steinmaus $\mathrm{C}$, Corley $\mathrm{D}$, et al. Meta-analysis: the risk of venous thromboembolism in patients with inflammatory bowel disease. Aliment Pharmacol Ther 2013;37:953-962.

42. Ananthakrishnan AN, Cagan A, Gainer VS, et al. Thromboprophylaxis Is Associated With Reduced Post-hospitalization Venous Thromboembolic Events in Patients With Inflammatory Bowel Diseases. Clin Gastroenterol Hepatol 2014;12:1905-1910.

43. Higgins PDR, Skup M, Mulani PM, et al. Increased Risk of Venous Thromboembolic Events With Corticosteroid vs Biologic Therapy for Inflammatory Bowel Disease. Clin Gastroenterol Hepatol 2015;13:316-321.

44. Sarlos P, Szemes K, Hegyi P, et al. Steroid but not biological therapy elevates the risk of venous thromboembolic events in inflammatory bowel disease. A meta-analysis. J Crohns Colitis 2017. Available at: https://academic.oup.com/ecco-jcc/advance-article/doi/10.1093/eccojcc/jjx162/4694102 [Accessed December 29, 2017].

45. Kristensen SL, Ahlehoff O, Lindhardsen J, et al. Disease Activity in Inflammatory Bowel Disease Is Associated with Increased Risk of Myocardial Infarction, Stroke and Cardiovascular Death - A Danish Nationwide Cohort Study Hernandez AV, ed. PloS One 2013;8:e56944.

46. Kirchgesner J, Beaugerie L, Carrat F, et al. Increased risk of acute arterial events in young patients and severely active IBD: a nationwide French cohort study. Gut 2017:gutjnl-2017-314015.

47. Singh S, Singh H, Loftus Jr. EV, et al. Risk of Cerebrovascular Accidents and Ischemic Heart Disease in Patients With Inflammatory Bowel Disease: A Systematic Review and Meta-analysis. Clin Gastroenterol Hepatol 2014;12:382-393.e1.

48. Rungoe $\mathrm{C}$, Basit $\mathrm{S}$, Ranthe MF, et al. Risk of ischaemic heart disease in patients with inflammatory bowel disease: a nationwide Danish cohort study. Gut 2013;62:689-694.

49. Roubille $C$, Richer $V$, Starnino $T$, et al. The effects of tumour necrosis factor inhibitors, methotrexate, non-steroidal anti-inflammatory drugs and corticosteroids on cardiovascular events in rheumatoid arthritis, psoriasis and psoriatic arthritis: a systematic review and meta-analysis. Ann Rheum Dis 2015;74:480-489.

50. Kirchgesner J, Andresen NN, Carrat F,et al. Exposure to combination therapy with thiopurines and anti-TNF agents is associated with reduced incidence of acute arterial events in patients with inflammatory bowel disease (IBD): a nationwide French cohort study. United Eur Gastroenetrol J 2017;5 (Supplement 1)

51. Roberts M, Russell LB, Paltiel AD, et al. Conceptualizing a Model: A Report of the ISPOR-SMDM Modeling Good Research Practices Task Force-2. Med Decis Making 2012;32:678-689.

52. Siebert U, Alagoz O, Bayoumi AM, et al. State-Transition Modeling: A Report of the ISPOR-SMDM Modeling Good Research Practices Task Force-3. Med Decis Making 2012;32:690-700. 
53. Lewis JD, Schwartz JS, Lichtenstein GR. Azathioprine for maintenance of remission in Crohn's disease: benefits outweigh the risk of lymphoma. Gastroenterology 2000;118:1018-1024.

54. Scott FI, Vajravelu RK, Bewtra M, et al. The benefit-to-risk balance of combining infliximab with azathioprine varies with age: a markov model. Clin Gastroenterol Hepatol 2015;13:302-309.e11.

55. Kirchgesner J, Beaugerie L, Carrat F, et al. Impact on Life Expectancy of Withdrawing Thiopurines in Patients with Crohn's Disease in Sustained Clinical Remission: A Lifetime Risk-Benefit Analysis. PloS One 2016;11:e0157191.

56. Torres J, Boyapati RK, Kennedy NA, et al. Systematic Review of Effects of Withdrawal of Immunomodulators or Biologic Agents From Patients With Inflammatory Bowel Disease. Gastroenterology 2015;149:1716-1730.

57. Greenberg D, Schwartz D, Vardi H, et al. Health-Related Utility Weights in a Cohort of Real-World Crohn's Disease Patients. J Crohns Colitis 2015:jjv167.

58. Tang DH, Harrington AR, Lee JK, et al. A systematic review of economic studies on biological agents used to treat Crohn's disease. Inflamm Bowel Dis 2013;19:2673-2694.

59. Nguyen GC, Sam J. Rising prevalence of venous thromboembolism and its impact on mortality among hospitalized inflammatory bowel disease patients. Am J Gastroenterol 2008;103:22722280.

60. Nicholls RJ, Clark DN, Kelso L, et al. Nationwide linkage analysis in Scotland implicates age as the critical overall determinant of mortality in ulcerative colitis. Aliment Pharmacol Ther 2010;31:1310-1321.

61. Ananthakrishnan AN, Donaldson T, Lasch K, et al. Management of Inflammatory Bowel Disease in the Elderly Patient: Challenges and Opportunities. Inflamm Bowel Dis 2017;23:882-893.

62. Woude CJ van der, Ardizzone S, Bengtson MB, et al. The second European evidenced-based consensus on reproduction and pregnancy in inflammatory bowel disease. J Crohns Colitis 2015;9:107-124.

63. Nguyen GC, Seow CH, Maxwell C, et al. The Toronto Consensus Statements for the Management of Inflammatory Bowel Disease in Pregnancy. Gastroenterology 2016;150:734-757.e1.

64. Shelton E, Laharie D, Scott Fl, et al. Cancer Recurrence Following Immune-Suppressive Therapies in Patients With Immune-Mediated Diseases: A Systematic Review and Meta-analysis. Gastroenterology 2016;151:97-109.e4.

65. Beaugerie L, Peyrin-Biroulet L. No Excess Cancer Recurrence After Immunosuppressive Drugs in a Meta-analysis of Cohorts of Patients With Immune-mediated Diseases: A Mirage Related to Propensity Bias? Gastroenterology 2017;152:304-306.

66. Siegel CA. Review article: explaining risks of inflammatory bowel disease therapy to patients. Aliment Pharmacol Ther 2011;33:23-32. 
67. Dulai PS, Siegel CA, Dubinsky MC. Balancing and communicating the risks and benefits of biologics in pediatric inflammatory bowel disease. Inflamm Bowel Dis 2013;19:2927-2936.

68. Johnson FR, Ozdemir S, Mansfield C, et al. Are adult patients more tolerant of treatment risks than parents of juvenile patients? Risk Anal 2009;29:121-136.

69. Thompson KD, Connor SJ, Walls DM, et al. Patients with Ulcerative Colitis Are More Concerned About Complications of Their Disease than Side Effects of Medications. Inflamm Bowel Dis 2016;22:940-947. 
Page 23

Table 1. Classification of infections that may occur in patients with inflammatory bowel disease

\begin{tabular}{|c|c|c|}
\hline Type & Definition & Impact \\
\hline $\begin{array}{l}\text { Benign infections } \\
\text { (e.g., cold, oral herpes flare) }\end{array}$ & $\begin{array}{l}\text { Are not life-threatening } \\
\text { Do not require hospitalization }\end{array}$ & $\begin{array}{l}\text { If repeated, may impair } \\
\text { quality of life }\end{array}$ \\
\hline $\begin{array}{l}\text { Serious infections } \\
\text { (e.g., intra-abdominal } \\
\text { abscess, severe } \\
\text { pneumonitis) }\end{array}$ & $\begin{array}{l}\text { Require hospitalization and/or } \\
\text { result in permanent disability }\end{array}$ & May be life-threatening \\
\hline $\begin{array}{l}\text { Opportunistic infections } \\
\text { (e.g., aspergillosis, severe } \\
\text { forms of varicella) }\end{array}$ & $\begin{array}{l}\text { Occur selectively or are } \\
\text { particularly severe in } \\
\text { immunocompromised patients }\end{array}$ & Are life-threatening \\
\hline
\end{tabular}


Table 2. Excess risk of infection and infection-related mortality in patients with inflammatory bowel disease exposed to corticosteroids, thiopurines and anti-Tumor Necrosis Factor (TNF) agents compared to patients not exposed to immunosuppressive drugs.

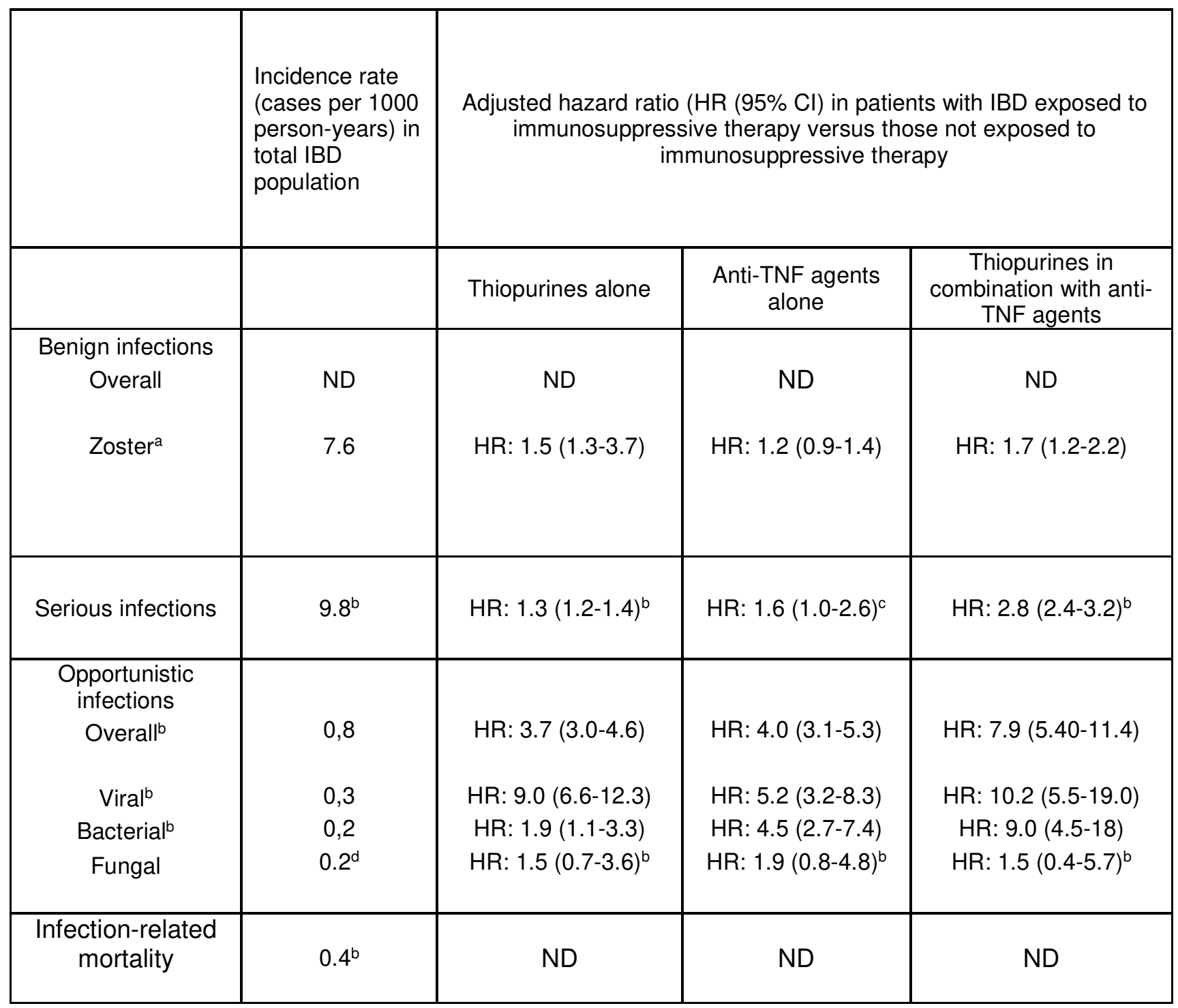

$\mathrm{Cl}$, confidence interval; ND, no data

${ }^{a}$ Data are from Khan et al. ${ }^{12}$

b Data are from Kirchgesner et al. ${ }^{5}$

${ }^{c}$ Data are from Nyboe-Andersen et al. ${ }^{6}$

${ }^{d}$ Data are from Lichstentein et al. ${ }^{17}$ 
Table 3. Absolute risk of cancer in patients with inflammatory bowel disease (IBD), and adjusted ratio of cancer in patients with IBD exposed to thiopurines and/or anti-Tumor Necrosis Factor (TNF) agents, compared to patients not exposed to immunosuppressive drugs.

\begin{tabular}{|c|c|c|c|c|}
\hline & \multirow{2}{*}{$\begin{array}{l}\text { Incidence rate } \\
\text { (cases per } 1000 \\
\text { person-years) in } \\
\text { total IBD } \\
\text { population }\end{array}$} & \multicolumn{3}{|c|}{$\begin{array}{c}\text { Adjusted rate ratio }(\mathrm{RR}(95 \% \mathrm{Cl})) \text {, hazard ratio }(\mathrm{HR}(95 \% \mathrm{Cl}) \text { or odds } \\
\text { ratio }(\mathrm{OR}(95 \% \mathrm{Cl}) \text { in patients with } \mathrm{IBD} \text { exposed to } \\
\text { immunosuppressive therapy versus those not exposed to } \\
\text { immunosuppressive therapy }\end{array}$} \\
\hline & & Thiopurines alone & $\begin{array}{l}\text { Anti-TNF agents } \\
\text { alone }\end{array}$ & $\begin{array}{l}\text { Thiopurines in } \\
\text { combination with anti- } \\
\text { TNF agents }\end{array}$ \\
\hline $\begin{array}{l}\text { All cancers, } \\
\text { excluding non- } \\
\text { melanocytic skin } \\
\text { cancers }\end{array}$ & $7.3^{\mathrm{a}}$ & $\mathrm{RR}: 1.4(1.2-1.7)^{\mathrm{b}}$ & RR: $1.1(0.9-1.4)^{\mathrm{a}}$ & ND \\
\hline \multicolumn{5}{|l|}{$\begin{array}{l}\text { Hematological } \\
\text { malignancies }\end{array}$} \\
\hline All & $0.5^{\mathrm{a}}$ & ND & RR: $0.9(0.4-1.9)^{a}$ & ND \\
\hline Lymphoma $^{b}$ & $0.3^{c}$ & HR: $2.6(2.0-3.4)^{\mathrm{C}}$ & HR: $2.4(1.6-3.6)^{\mathrm{C}}$ & HR: $6.1(1.3-4.2)^{\mathrm{C}}$ \\
\hline \multicolumn{5}{|l|}{ Skin cancers } \\
\hline $\begin{array}{l}\text { Non melanocytic } \\
\text { skin cancer }\end{array}$ & $9.1^{d}$ & OR: $1.9(1.7-2.1)^{d}$ & OR: $1.1(0.9-1.4)^{d}$ & ND \\
\hline Melanoma & $0.4^{a}$ & OR: $1.1(0.7-1.7)^{d}$ & OR: $1.9(1.1-3.3)^{d}$ & ND \\
\hline Urinary tract cancer & $0.3^{\mathrm{a}}$ & HR: $2.8(1.0-7.7)^{\mathrm{e}}$ & RR: $1.6(0.6-4.2)^{\mathrm{a}}$ & ND \\
\hline
\end{tabular}

$\mathrm{Cl}$, confidence interval; ND, no data

a Data are from Nyboe-Andersen et al. ${ }^{33}$

${ }^{b}$ Data are from Pasternak et al. ${ }^{26}$

${ }^{\mathrm{c}}$ Data are from Lemaitre et al. ${ }^{34}$

${ }^{\mathrm{d}}$ Data are from Long et al. ${ }^{30}$

e Data are from Bourrier et al. ${ }^{32}$ 


\section{Immune-suppressive therapy in IBD may:}

Decrease (benefit)

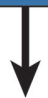

Provoke (risk)

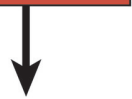

Complications of immunosuppression

Related to immunosuppression

- various infections (including opportunistic infections)

- intestinal lesions (abscesses)

- intravenous devices

- malnutrition

- surgery for IBD

Cancers $\quad$ Related to chronic inflammation

- colorectal cancer

- small bowel adenocarcinoma

- anal cancer

Cardio-

vascular

events
Related to immunosuppression

- mainly lymphomas and skin cancers
Related to inflammation, hospitalization, or surgery for IBD

- venous thromboembolic events

- acute arterial events

\section{Provoke (risk)}

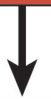

Drug-class specific complications

- Bone marrow suppression (thiopurines)

- Interstitial pneumonitis (methotrexate)

- Leuko-encephalopathy (anti-TNF) 
Benign infections

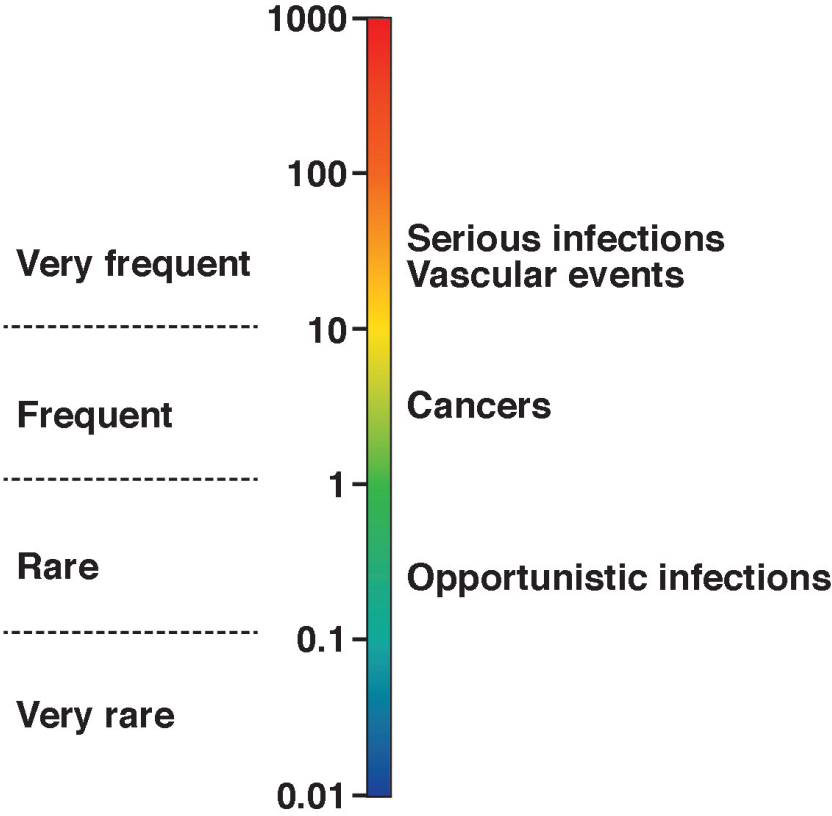

Events per 1000 patient-years (percentages of risk for a ten-year period) 


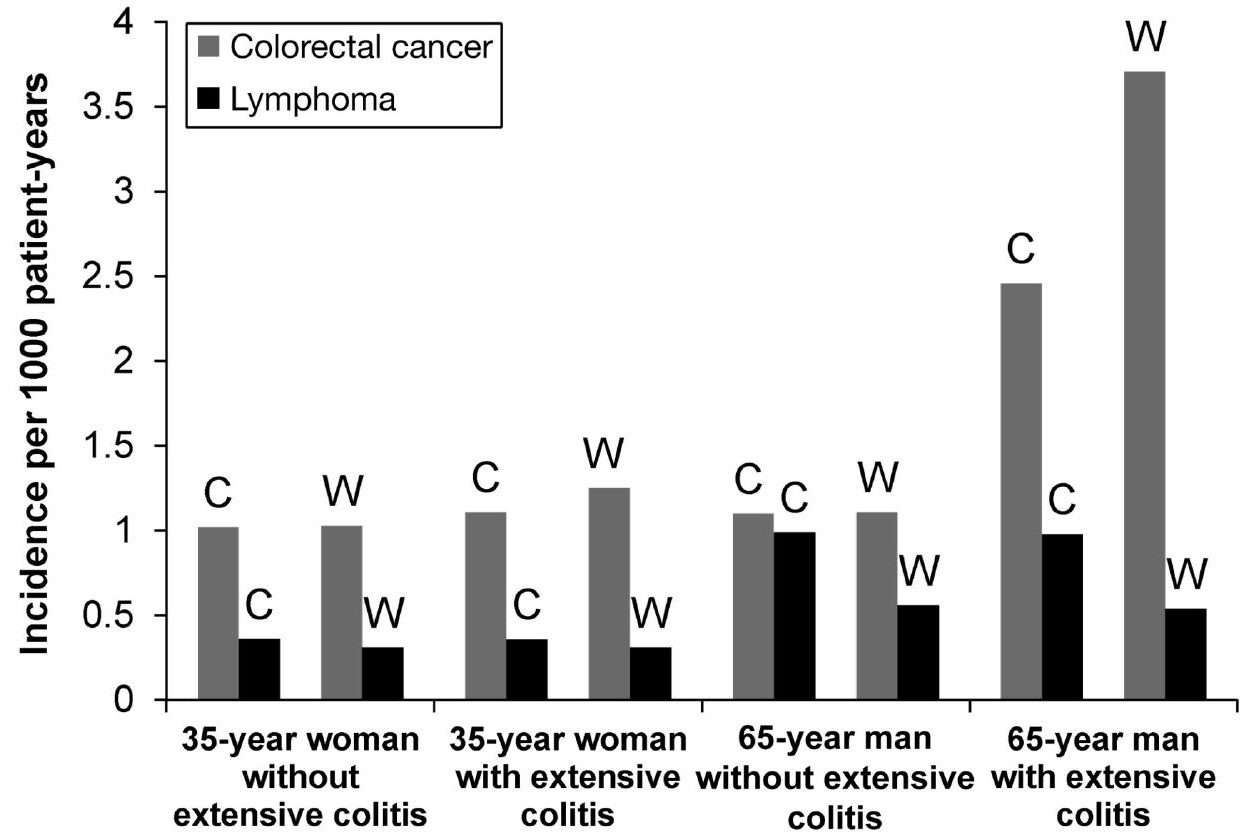

